\title{
Clinical recognition and recording of alcohol disorders by clinicians in primary and secondary care: meta-analysis
}

Alex J. Mitchell, Nick Meader, Vicky Bird and Maria Rizzo

\section{Background}

Clinicians have considerable difficulty identifying and helping those people with alcohol problems but no previous study has looked at this systematically.

\section{Aims}

To determine clinicians' ability to routinely identify broadly defined alcohol problems

\section{Method}

Data were extracted and rated by two authors, according to PRISMA standard and QUADAS criteria. Studies that examined the diagnostic accuracy of clinicians' opinion regarding the presence of alcohol problems as well as their written notation were evaluated.

\section{Results}

A comprehensive search identified 48 studies that looked at the routine ability of clinicians to identify alcohol problems (12 in primary care, 31 in general hospitals and 5 in psychiatric settings). A total of 39 examined alcohol use disorder, 5 alcohol dependence and 4 intoxication. We separated studies into those using self-report and those using interview. The diagnostic sensitivity of primary care physicians (general practitioners) in the identification of alcohol use disorder was $41.7 \%(95 \% \mathrm{Cl} 23.0-61.7)$ but alcohol problems were recorded correctly in only $27.3 \%$ (95\% Cl 16.9-39.1) of primary care records. Hospital staff identified $52.4 \%$ (95\% Cl 35.9-68.7) of cases and made correct notations in $37.2 \%$ (95\% Cl $28.4-46.4)$ of case notes. Mental health professionals were able to correctly identify alcohol use disorder in $54.7 \%$ (95\% $\mathrm{Cl} 16.8-89.6)$ of cases. There were limited data regarding alcohol dependency and intoxication. Hospital staff were able to detect $41.7 \%$ (95\% Cl 16.5-69.5) of people with alcohol dependency and $89.8 \%$ (95\% Cl 70.4-99.4) of those acutely intoxicated. Specificity data were sparse.

\section{Conclusions}

Clinicians may consider simple screening methods such as self-report tools rather than relying on unassisted clinical judgement but the added value of screening over and above clinical diagnosis remains unclear.

\section{Declaration of interest}

None.
Alcohol problems are a significant public health problem. ${ }^{1,2}$ Alcohol consumption has been estimated to cause $3.8 \%$ of all deaths and $4.6 \%$ of disability. ${ }^{3}$ Alcohol problems in general include alcohol use disorder, alcohol dependence and acute intoxication. Alcohol use disorders include a spectrum of excessive drinking often also described as alcohol abuse (DSM-IV), ${ }^{4}$ hazardous drinking $(\mathrm{WHO})^{5}$ or harmful drinking (ICD-10 ${ }^{6}$ (see Appendix 1). In the general population hazardous drinking is seen in $30-40 \%,{ }^{7}$ with lifetime alcohol misuse or dependence found in about $10 \%$ compared with $16-36 \%$ of out-patients. ${ }^{8,9}$ In primary care approximately $7-30 \%$ of attendees have at-risk drinking or an alcohol use problem. ${ }^{2,10-12}$ In hospital settings the point prevalence of alcohol use disorder varies between 7 and $25 \%{ }^{13-18}$ and approximately $4 \%$ have alcohol dependence. ${ }^{19}$ In psychiatric out-patients with serious mental illness, a recent meta-analysis showed rates of $10 \%$ (current use) and $20 \%$ (lifetime use) for alcohol use disorder. ${ }^{20}$ The highest rates are seen in psychiatric in-patients where prevalence rates may be as high as $50 \% .{ }^{21-23}$ In spite of these high prevalence rates it seems that only a minority of alcohol problems are detected and treated. Studies conducted in the USA, Australia, UK and Finland indicate that clinicians frequently do not screen for alcohol use disorder and fail to address the problem in at least a third to a half of cases even when the diagnosis is known. ${ }^{24-28}$ In most cases, diagnosis is made by clinical judgement without the use of scales, blood tests or reference to diagnostic criteria. ${ }^{29,30}$ Patient surveys suggest that only $30-40 \%$ are asked about their alcohol habits ${ }^{31-33}$ and a small percentage of those with alcohol problems report receiving advice to cut down. ${ }^{34}$ Several effective treatment packages including brief alcohol interventions have been developed and are potentially effective. ${ }^{35-37}$ However, such interventions can only be effective when alcohol problems are recognised. Numerous studies of screening tools and biomarkers have been conducted but it is important to clarify how much improvement in the identification of alcohol problems occurs with their use above and beyond that achieved from routine clinical judgement alone. ${ }^{38}$ Early research suggests that about a third of individuals with alcohol problems are detected by their general practitioner. ${ }^{28}$ The comparable detection rate from general hospital and psychiatric settings is unknown, although some previous work has suggested that hospital specialists detect most people with drinking problems at admission. ${ }^{39}$

The aim of this study was to clarify accuracy of clinical judgement as well as clinical recording of clinicians working in (a) primary care, (b) general hospital and (c) psychiatric settings in identifying broadly defined alcohol problems. We hypothesised that mental health specialists would have the greatest success and primary care doctors the least success when working without assistance of scales or tools.

\section{Method}

\section{Inclusion and exclusion criteria}

The principal inclusion criteria were studies that examined the clinical judgement and clinical recording of clinicians in the identification of those with alcohol problems. We defined alcohol problems broadly to give a representative picture of routine 
practice. We grouped these problems into alcohol use disorder with and without dependence. We allowed studies to use a selfreport or interview-based criterion definition of alcohol use disorder. Although we did not specifically exclude ICD-10-based studies, all interview-based studies used DSM criteria (Appendix 1). In an attempt to minimise heterogeneity we looked at studies examining acute intoxication and alcohol dependence separately from alcohol use disorder without intoxication or dependence. We excluded studies that did not present data on alcohol use, were based on vignettes, had insufficient primary data or failed to employ an adequate criterion standard (e.g. studies based on self-reported alcohol use). ${ }^{40-46}$

\section{Search and information sources}

A systematic search, critical appraisal and meta-analysis were conducted. The following abstract databases were searched from inception to September 2011. In MEDLINE/Embase (266 hits) and PsycINFO (20 hits), relevant keywords, MESH terms, title terms and limits were applied (available from the author on request). In four full-text collections (Science Direct, Ingenta Select, Ovid Full text, Blackwell-Wiley Interscience) the search terms were used as a full text search and citation search (261 hits). The abstract databases SCOPUS (179 hits) and Web of Knowledge (113 hits) were searched, using relevant search terms as a text word search, and using key papers in a reverse citation search. Non-English language articles were searched and one relevant study was found. We also contacted several experts in the field for unpublished and very recently published work.

\section{Data extraction and appraisal}

We adhered to standards in the PRISMA guidelines for metaanalyses. ${ }^{47}$ Data extraction was conducted independently by two authors using a data extraction form in Microsoft excel. The form was developed from previous systematic reviews of diagnostic accuracy according to principles of PRISMA and the Cochrane Collaboration (available from the author on request). ${ }^{48}$ Variables extracted were country of study, setting (e.g. primary care, general hospital), patient characteristics (e.g. age, gender), reference standard (including cut-off if relevant), method used to determine clinician judgement, sample size, positive cases and negative cases (as identified by reference standard), sensitivity, specificity, true positives (i.e. clinician judgement and reference standard both suggest alcoholism), false positives (i.e. clinician judgement suggests alcoholism but reference standard does not), false negatives (clinician judgement indicates no alcoholism but reference standard suggests alcoholism) and true negatives (both clinician judgement and reference standard both judge no alcoholism). To establish validity of the data extraction for the primary outcomes, true positive, false positives, false negatives and true negatives extracted from papers were recalculated from prevalence, sensitivity and specificity data in order to identify any inconsistencies or errors in extraction. Any inconsistencies were resolved by double-checking data from the paper and discussion with one of the authors (A.J.M.). Appraisal of each article was conducted by all authors independently using QUADAS. ${ }^{49}$ This is a standardised quality appraisal form and is the recommended tool for a number of organisations such as the Cochrane Collaboration and the National Institute for Health and Clinical Excellence.

\section{Meta-analysis}

Given high heterogeneity, we used random effects bivariate metaanalysis to synthesise the data and provide pooled estimates of sensitivity and specificity using the metandi commands in Stata 10 on Windows. This method fits a two-level model, with independent binomial distributions for the true positives and true negatives conditional on the sensitivity and specificity in each study, and a bivariate normal model for the logit transforms of sensitivity and specificity between studies. ${ }^{50}$ A summary receiver operator characteristic (ROC) curve, where each data point represents a separate study, was then constructed using the bivariate model to produce a $95 \%$ confidence ellipse within ROC space. Heterogeneity was assessed using the $I^{2}$ statistic. $^{51}$ Partial verification bias, differential verification bias and incorporation bias was assessed for each study (online Table DS1). Finally, publication bias was assessed formally using Begg-Mazumdar's test. ${ }^{52}$

\section{Results}

\section{Study description and methods}

We identified 48 studies of clinical accuracy including 39 on alcohol use disorder, 4 concerning intoxication and 5 examining alcohol dependence (Fig. 1). The sample size of individual studies ranged from 35 to 3014 individuals (mean 490.6, s.d.=644.7). Twenty-one studies identified alcohol use disorder on the basis of a structured interview, four intoxication studies used blood alcohol concentration and the remainder used self-report measures of alcohol use (online Table DS2). High heterogeneity was found for most analyses (I ranged from 92.0 to $94.5 \%$ depending on analysis). Publication bias was assessed using funnel plots but no evidence of bias was detected (Fig. 2).

We examined the prevalence of each type of alcohol problem according to setting. In primary care the pooled prevalence of alcohol use disorder was $16.7 \%$ (95\% CI 10.0-24.6). It was $12.1 \%$ (95\% CI $7.2-18.0$ ) when identified by interview and $22.7 \%$ (95\% CI 10.5-37.9) when identified by self-report. In hospital settings the prevalence of alcohol use disorder was $33.5 \%$ (95\% CI 16.2-53.5\%) (Martin et $a l^{53}$ was excluded from the prevalence calculation as the study pre-selected a high-risk sample). However, the prevalence was $43.4 \%$ (95\% CI 5.1-87.5) when identified by interview and $28.1 \%$ (95\% CI 20.5-36.5) when identified by self-report. In mental health settings the prevalence of alcohol use disorder was $21.7 \%$ (95\% CI 10.4-35.7), with insufficient studies to stratify by self-report/interview. Finally, the prevalence of alcohol dependence was 12.1\% $(n=4,95 \%$ CI 9.3-15.1) in hospital settings, whereas the prevalence of intoxication reached $52 \%(n=2,95 \%$ CI 7.7-94.0) identified by analysing blood alcohol levels in emergency departments.

\section{Identification by primary care physicians}

\section{Alcohol use disorder}

Across 12 studies, involving 10997 people with problem drinking, primary care physicians recorded alcohol problems in medical records in $27.3 \%$ (95\% CI $16.9-39.1)$, but actually recognised alcohol use disorder in $41.7 \%$ (95\% CI 23.0-61.7) using clinical judgement (Table 1). In studies relying on interview-based gold standard detection the sensitivity was $44.0 \%$ (95\% CI $21.4-$ 68.0). There were only two studies with specificity data, both based on clinical judgement, and primary care physicians correctly reassured $93.1 \%$ (95\% CI 86.7-97.6) of people without a drinking problem (detection specificity). At a prevalence of $20 \%$, the positive predictive value would be $60.2 \%$ and the negative predictive value $86.5 \%$. Thus, a primary care practitioner would typically identify 8 cases, missing 12 . They would correctly identify 75 non-drinkers, falsely diagnosing 5 . Thus the fraction correctly identified would be $83 \%$. 


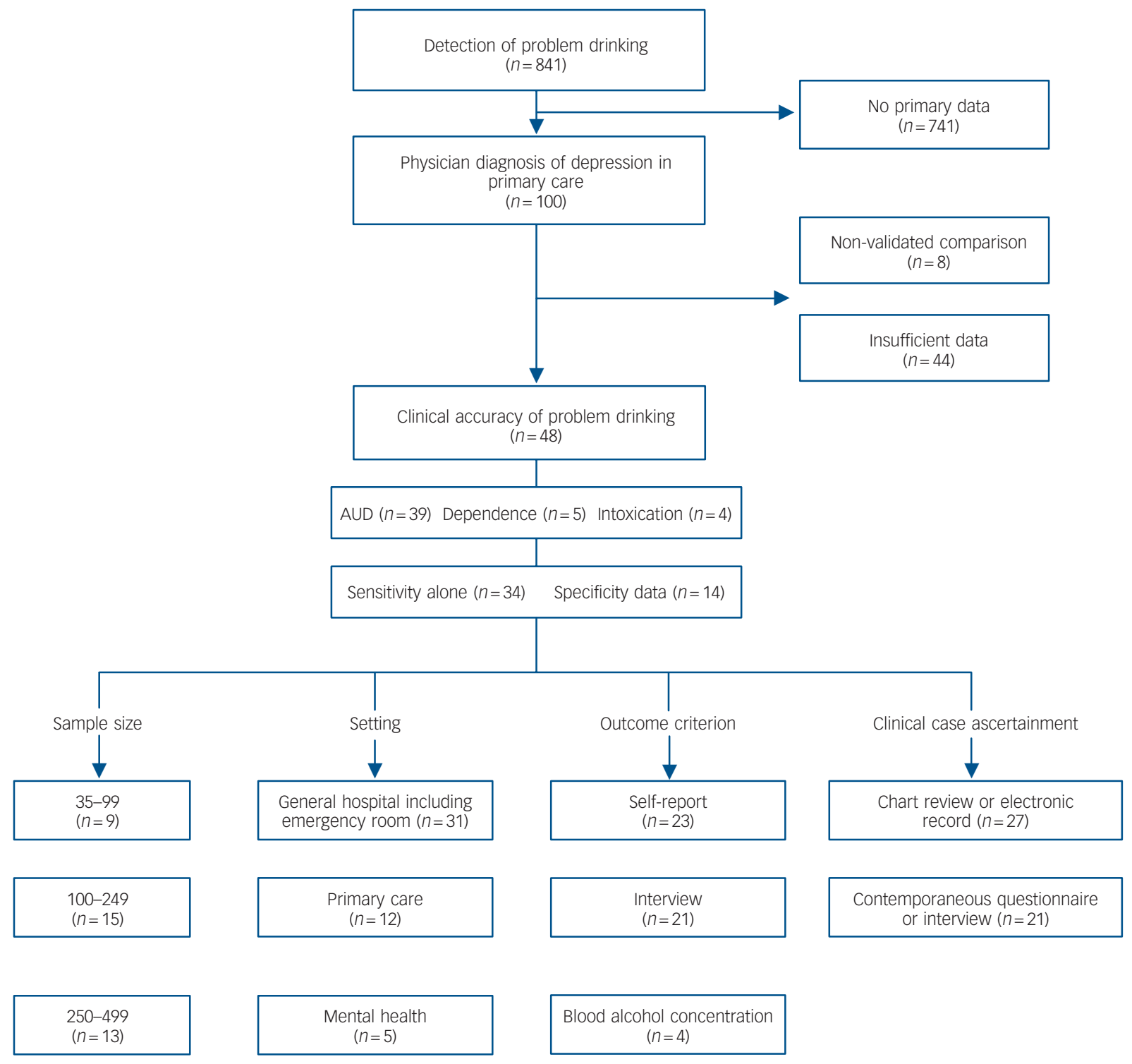

\section{0 or higher $(n=11)$}

\section{Fig. 1 QUOROM overview of studies.}

AUD, alcohol use dependence. Sample size refers to raw data extracted.

\begin{tabular}{|c|c|c|c|c|c|c|}
\hline \multirow[b]{2}{*}{ Professional group } & \multicolumn{2}{|c|}{ Alcohol use disorder } & \multicolumn{2}{|c|}{ Alcohol dependence } & \multicolumn{2}{|c|}{ Alcohol intoxication } \\
\hline & $\begin{array}{l}\text { Sensitivity } \\
\%(95 \% \text { Cl) }\end{array}$ & $\begin{array}{l}\text { Specificity } \\
\%(95 \% \text { Cl) }\end{array}$ & $\begin{array}{l}\text { Sensitivity } \\
\%(95 \% \mathrm{Cl})\end{array}$ & $\begin{array}{l}\text { Specificity } \\
\%(95 \% \text { Cl) }\end{array}$ & $\begin{array}{l}\text { Sensitivity } \\
\%(95 \% \text { Cl) }\end{array}$ & $\begin{array}{l}\text { Specificity } \\
\%(95 \% \mathrm{Cl})\end{array}$ \\
\hline \multicolumn{7}{|l|}{ Clinical judgement } \\
\hline Primary care physicians & $41.7(23.0-61.7)$ & $93.1(86.7-97.6)$ & No studies & No studies & No studies & No studies \\
\hline Hospital specialists & $52.4(35.9-68.7)$ & $88.2(80.9-93.9)$ & No studies & No studies & $89.8(70.4-99.4)$ & $61.4(11.4-98.7)$ \\
\hline Mental health professionals & $54.7(16.8-89.6)$ & $83.6(56.3-98.8)$ & No studies & No studies & No studies & No studies \\
\hline \multicolumn{7}{|l|}{ Clinical recording (chart notation) } \\
\hline Primary care physicians & $27.3(16.9-39.1)$ & No studies & No studies & No studies & No studies & No studies \\
\hline Hospital specialists & $37.2(28.4-46.4)$ & $95.2(94.2-96.1)$ & $41.7(16.5-69.5)$ & No studies & 75.6 (68.1-82.3). & No studies \\
\hline Mental health professionals & $28.2(15.0-44.9)^{a}$ & No studies & No studies & No studies & No studies & No studies \\
\hline
\end{tabular}




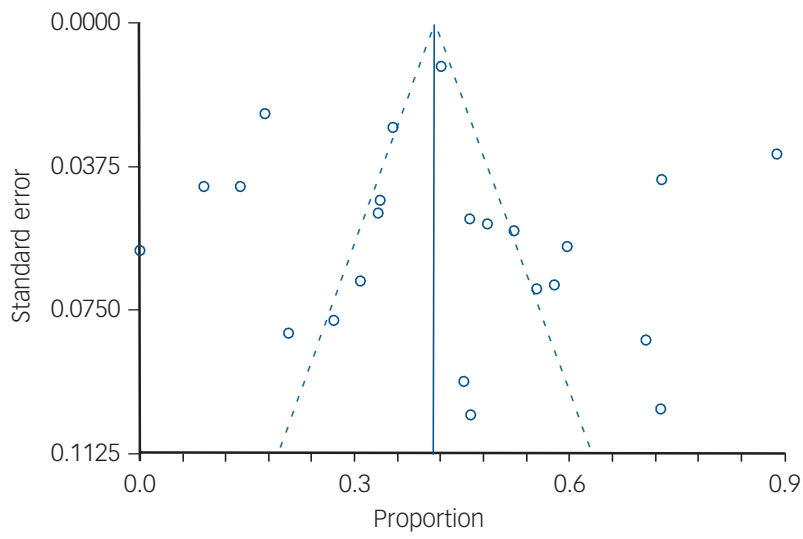

Fig. 2 Bias assessment plot.

Begg-Mazumdar: Kendall's tau $=0.15415, P=0.3194$; Egger: bias 0.504955 (95\% $\mathrm{Cl}-2.05$ to 2.98$), P=0.7333$

\section{Alcohol dependence and alcohol intoxication}

No studies were found.

\section{Identification by hospital staff in medical settings}

\section{Alcohol use disorder}

Across 23 studies involving 10837 people with alcohol use disorder, health professionals correctly recorded alcohol problems in $37.2 \%$ (95\% CI 28.4-46.4) of case notes. Based on clinical judgement, at interview they correctly identified 52.4\% (95\% CI 35.9-68.7). There was no difference in detection sensitivity when stratified by gold standard (robust clinical interview) 41.2\% (95\% CI 28.8-54.2) v. self-report $42.7 \%$ (95\% CI 31.1-54.6). In nine studies reporting specificity, hospital staff identified $93.1 \%(95 \%$ CI 89.1-96.3) of those without problem drinking with no difference by case ascertainment or outcome method.

At a prevalence of $20 \%$, the positive predictive value would be $52.5 \%$ and the negative predictive value $88.2 \%$. Thus, hospital doctors would typically identify 10 cases, missing 10 . Hospital doctors would typically correctly identify 71 non-drinkers, falsely diagnosing 9. Thus, the fraction correctly identified would be $81 \%$.

\section{Alcohol dependence and alcohol intoxication}

There were four studies assessing the identification of alcohol dependence in hospital settings. Hospital staff accurately recorded $41.7 \%$ (95\% CI 16.5-69.5) of such cases in medical notes. However, no data were reported on specificity in these settings.

Four studies examined the ability of doctors and nurses working in trauma centres to identify acute alcohol intoxication (defined by a high blood alcohol concentration). Health professionals were able to identify intoxication in $89.8 \%(95 \%$ CI 70.4-99.4) of cases based on clinical judgement and recorded this in the notes in 75.6\% (95\% CI 68.1-82.3). However, their specificity (based on clinical judgement) was low at $61.4 \%$ $(n=2,95 \%$ CI 11.4-98.7).

\section{Identification by mental health professionals}

\section{Alcohol use disorder}

We located four studies involving a small sample of 784 patients, but as there was only one study using a chart review method (showing a sensitivity of $28.2 \%$ ), we were only able to pool studies

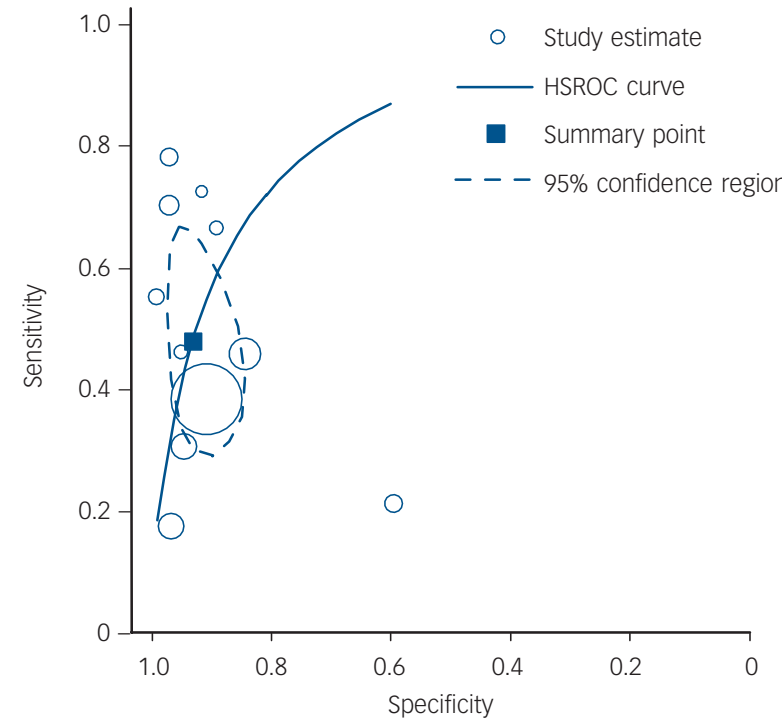

Fig. 3 Hierarchical summary receiver operator characteristic (HSROC) curve for clinical identification of alcohol use disorder.

Sampled data from Gentilello et al ${ }^{55}$ only includes detection of alcohol use disorder by doctors.

of clinical judgement, reducing the sample size to 384 . Mental health professionals identified $54.7 \%$ (95\% CI 16.8-89.6) of those with alcohol use disorder. Based on clinical judgement, their detection specificity was $83.6 \%$ (95\% CI 56.3-98.8). At a prevalence of $20 \%$, the positive predictive value would be $45.4 \%$ and negative predictive value $88.1 \%$. Thus, a mental health professional would typically identify 11 cases, missing 9. They would correctly identify 67 non-drinkers, falsely diagnosing 13 . Thus, the fraction correctly identified would be $78 \%$.

\section{Alcohol dependence and alcohol intoxication}

Only one small study was found. Rienzi ${ }^{54}$ reported that mental health practitioners had a sensitivity of $82.9 \%$ (95\% CI $67.3-$ 91.9) when looking for self-reported alcohol dependency (defined using the Michigan Alcoholism Screening Test (MAST)).

Figure 3 shows the results for the hierarchical summary ROC curve analysis for clinical identification of alcohol use disorder.

\section{Discussion}

\section{Main findings}

We found 39 studies examining the clinical identification of alcohol use disorder, 5 studies involving alcohol dependence and 4 involving acute alcohol intoxication, with a total sample of 23472 participants. Although the overall sample size was large there was sparse data on dependence and intoxication, especially in mental health settings (Table 1). Our findings indicate that all healthcare professionals have considerable difficulty with the identification of problem drinking in clinical practice, identifying about half of those with alcohol use disorder based on clinical judgement and correctly recording alcohol use disorder in the notes in only one in three cases. It should be noted that this data were based on single assessments to inform clinical opinion. Only one study examined the effect of cumulative assessment, finding that detection sensitivity improved from 16 to $34 \%$ after three consultations. ${ }^{56}$ Previous studies have found that clinicians have most difficulty identifying individuals with milder alcohol 
problems and better success with dependence but we found no significant difference. ${ }^{46}$ The most successful group were emergency department specialists who were able to identify acute alcohol intoxication in nine out of ten people. This is in itself important, as at least 33\% of people seen in the emergency department for trauma have evidence of legal intoxication. ${ }^{55,57}$ However, even here emergency department specialists made a significant number of false positive errors.

Using clinical judgement primary care physicians identified about four in ten of attendees with alcohol use disorder, although their medical records were accurate in less than three out of ten. This is in line with previous work suggesting that most of those presenting in primary care are not detected routinely. ${ }^{28}$ Recognition by hospital specialists and mental health professionals has been much less discussed. ${ }^{44}$ Hospital staff also had difficulty with recognition with about half of people with alcohol use disorder identified. This is important because alcohol use disorder can exacerbate severity of illness and prognosis in people with several mental disorders such as schizophrenia and depression. ${ }^{58-60}$ Our finding of lower accuracy in indentifying problems among mental health professionals may be surprising but it has been previously found that alcohol problems are often not discussed even in mental health settings. ${ }^{61,62}$ Further, most mental health practitioners are not expert in alcohol problems, rarely use standardised instruments for alcohol problems and have variable access to dedicated specialist alcohol services. ${ }^{63-65}$

\section{Barriers to the recognition of alcohol problems}

Many factors have been cited as barriers to appropriate and prompt recognition. These include clinician confidence as to what constitutes alcohol misuse, ${ }^{66}$ inadequate training, ${ }^{67}$ lack of contractual incentives, ${ }^{68}$ lack of time, ${ }^{69}$ fear of labelling due to the stigma associated with substance misuse ${ }^{70}$ and a belief that patients will not honestly disclose their drinking practices. ${ }^{71-73}$ In most cases patients accept being questioned about their drinking habits. ${ }^{74,75}$ Our data on the similar prevalence of alcohol problems by self-report compared with interview and lack of substantial diagnostic differences by criterion reference do not support the hypothesis that people will not disclose their drinking history if asked in a sensitive manner. Therefore we suggest that the most significant modifiable predictor remains the willingness of the clinician to ask about alcohol habits appropriately. ${ }^{76}$ In self-report surveys, health professionals report that they often enquire about drinking behaviours. ${ }^{77-79}$ Yet they also express the belief that clinical questions will not be answered honestly by patients ${ }^{70}$ and are concerned that asking about drinking might harm the patient-provider relationship. ${ }^{72,80}$

Observational studies of clinician enquiry show that, in general, screening for alcohol problems is not routine in primary care ${ }^{29,30,81,82}$ or in specialist settings. ${ }^{83}$ Several studies found that clinicians discuss alcohol use in about $10-15 \%$ of consultations but few discussions are specifically prompted by concerns over drinking habits. ${ }^{84-86,83}$ On videotaped or observed interviews, alcohol-related discussions were often superficial and yielded little information regarding patients' drinking practices. ${ }^{82,87,88}$ Interviews where at-risk drinking discussions took place typically lasted only $1-2$ min..$^{89,90}$ Of those clinicians that look for alcohol problems, nearly all prefer asking quantity-frequency questions, about a third say they use the CAGE questions, and 15\% cite use of biochemical markers. ${ }^{83,91,92}$ D'Amico et al examined the practices of physicians towards over 7000 individuals visiting them. ${ }^{93}$ The practitioners asked $29 \%$ about their drinking (and $44 \%$ of problem drinkers about their drinking) over 1 year. Of those asked about alcohol problems, only $21 \%$ received advice
(49\% in the case of problem drinkers). ${ }^{93}$ Clinicians are least likely to raise the subject of problem drinking with White people, women and widows, ${ }^{86}$ prioritising discussion with healthier, younger males who misuse tobacco and alcohol. ${ }^{94}$ Less studied is the issue of whether clinicians may also find distinguishing problematic alcohol use from non-problematic use difficult.

In response to these concerns the Institute of Medicine, the National Institute on Alcohol Abuse and Alcoholism (NIAAA), the American Medical Association and the American Society of Addiction Medicine have all recommended that clinicians routinely ask patients about alcohol use. ${ }^{79,95-97}$ However, the Scottish Intercollegiate Guidelines Network advocates clinical assessment with judicious use of questionnaires only where there is suspicion of alcohol problems. ${ }^{98}$ The NIAAA and the US Preventive Services Task Force (USPSTF) recommend population screening to identify problem drinking; that is, clinicians should ask all attendees whether they drink, and assess the specific quantity, frequency and pattern of consumption, but they did not recommend a specific tool. ${ }^{99}$ In 2004 the USPSTF recommended that screening should be accompanied by behavioural counselling interventions to reduce alcohol misuse by adults in primary care settings. ${ }^{100}$ The NIAAA also recommended targeted screening (case finding) in that all patients who drink alcohol should be screened with the CAGE questions. ${ }^{101}$ To date, variations of the AUDIT (Alcohol Use Disorder Identification Test), CAGE and MAST have been the most common questionnaires for alcohol problems but these tools are difficult to use in a primary care practice. ${ }^{72,79,82,102,103}$ No single laboratory test or combination of tests has been shown to be appropriate for screening. ${ }^{104,105}$

\section{Limitations}

The main limitation in this data synthesis is lack of data from some settings and a lack of consistency in terminology for alcohol use disorder. ${ }^{106,107}$ It is disappointing that few studies were conducted in Europe, and none in the UK. Some problems in terminology are to be anticipated given we have examined studies spanning more than 25 years of clinical practice. A second limitation is the reliance on self-report criterion methods such as the CAGE, AUDIT and MAST in some studies. However, we adjusted for this by examining both interview-based and selfreport standards separately. In primary care and medical settings there was no difference in sensitivity or specificity but in mental health settings, in studies relying on an interview-based gold standard, detection sensitivity was significantly lower $36.0 \%$ (95\% CI 16.5-58.2) compared with self-report 79.8\% (95\% CI 70.0-88.1). In addition, we found no statistically significant difference in the prevalence of alcohol use disorder whether defined by interview or self-report.

\section{Implications}

Given the clear findings that most, if not all health professionals struggle to accurately identify those with alcohol problems (including dependency) is there any evidence that interventions improve recognition rates? There is some evidence that education programmes can improve diagnostic habits. ${ }^{108}$ A meta-analysis of 15 methods in 12 trials aimed at increasing primary care practitioner rates of screening for, and giving advice about, hazardous and harmful alcohol consumption concluded it is possible to increase the engagement of physicians although effects of identification of alcohol problems were unclear. ${ }^{109}$ There is an urgent need to trial combined screening, education and brief alcohol interventions in adequate samples in both mental health 
and general hospital settings. We suggest that such trials specifically measure detection sensitivity and detection specificity as well as patient outcomes. We also suggest that such trials compare the performance of screening against unassisted clinical accuracy in order to clarify which methods most help clinicians identify people with problem drinking.

Alex J. Mitchell, MBBS, Department of Psycho-oncology, Leicester Partnership Trus and Department of Cancer Studies \& Molecular Medicine, Leicester Royal Infirmary, Leicester; Nick Meader, PhD, National Collaborating Centre for Mental Health, Roya college of Psychiatrists' Research Unit, London and CORE, University College London, Research Department of Clinical, Educational and Health Psychology, London; Vicky Bird, BSc, Maria Rizzo, MSc, National Collaborating Centre for Mental Health, London, UK

Correspondence: Alex J. Mitchell, Leicester General Hospital, Leicester Partnership Trust, Leicester LE5 4PW, UK. Email: alex.mitchel|@leicspart.nhs.uk

First received 22 Dec 2010, final revision 19 Sep 2011, accepted 19 Dec 2011

\section{Appendix}

\section{Definitions of alcohol problems}

\section{Our catagorisation}

Alcohol use disorder

Alcohol use disorder with dependence

\section{Source definition}

Hazardous use $(\mathrm{WHO})^{5}$ Alcohol abuse (DSM-IV-TR) ${ }^{4}$ Alcoholism or alcoholic (primary authors' own definition, from original publications, see online Table DS2)

Risky drinking or at-risk drinking (primary authors' own definition, from original publications, see online Table DS2)

Alcohol dependence (DSM-IV-TR) ${ }^{4}$

\section{Acknowledgements}

Thanks to the staff of the postgraduate library, Leicester General Hospital. Thanks also to Alex Sutton, Professor of Medical Statistics, University of Leicester for statistical advice.

\section{References}

1 Room R, Babor T, Rehm J. Alcohol and public health. Lancet 2005; 365: 519-30.

2 Saitz, R. Clinical practice. Unhealthy alcohol use. New Engl J Med 2005; 352 596-607.

3 Rehm J, Mathers C, Popova S, Thavorncharoensap M, Teerawattananon Y, Patra J. Global burden of disease and injury and economic cost attributable to alcohol use and alcohol-use disorders. Lancet 2009; 373: 2223-33.

4 American Psychiatric Association. Diagnostic and Statistical Manual of Mental Disorders (4th edn, revised) (DSM-IV-TR). APA, 2000

5 World Health Organization. Lexicon of Alcohol and Drug Terms Published by the World Health Organization. WHO, 2012.

6 World Health Organization. The ICD-10 Classification of Mental and Behavioural Disorders: Clinical Descriptions and Diagnostic Guidelines. WHO, 1992.

7 Compton WM, Conway KP, Stinson FS, Colliver JD, Grant BF. Prevalence, correlates, and comorbidity of DSM-IV antisocial personality syndromes and alcohol and specific drug use disorders in the United States: results from the national epidemiologic survey on alcohol and related conditions. J Clin Psychiatry 2005; 66: 677-85.

8 O'Connor PG, Schottenfeld RS. Patients with alcohol problems. New Engl J Med 1998; 338: 592-602

9 National Institute on Alcohol Abuse and Alcoholism. Tenth Special Report to the US Congress on Alcohol and Health. NIH Publication No. 00-3769. Department of Health and Human Services, 2000.

10 Reid MC, Fiellin DA, O'Connor PG. Hazardous and harmful alcohol consumption in primary care. Arch Intern Med 1999; 159: 1681-9.

11 Buchsbaum DG, Buchanan RG, Lawton MJ, Schnoll SH. Alcohol consumption patterns in a primary care population. Alcohol Alcohol 1991; 26: 215-20.
12 Fiellin DA, Reid MC, O'Connor PG. Screening for alcohol problems in primary care: a systematic review. Arch Intern Med 2000; 160: 1977-89.

13 Gerke P, Hapke U, Rumpf HJ, John U. Alcohol-related diseases in general hospital patients. Alcohol Alcohol 1997; 32: 179-84.

14 John U, Rumpf H-J, Hapke U. Estimating prevalence of alcohol abuse and dependence in one general hospital: an approach to reduce sample selection bias. Alcohol Alcohol 1999; 34: 786-94

15 Jarque-López A, González-Reimers E, Rodríguez-Moreno F, Santolaria-Fernández F, López-Lirola A, Ros-Vilamajo R, et al. Prevalence and mortality of heavy drinkers in a general medical hospital unit. Alcohol Alcohol 2001; 36: 335-8.

16 Smothers BA, Yahr HT, Sinclair MD. Prevalence of current DSM-IV alcohol use disorders in short-stay, general hospital admissions, United States, 1994. Arch Intern Med 2003; 163: 713-9.

17 Roche AM, Freeman T, Skinner N. From data to evidence, to action: findings from a systematic review of hospital screening studies for high risk alcohol consumption. Drug Alcohol Depend 2006; 83: 1-14.

18 Santora PB, Hutton HE. Longitudinal trends in hospital admissions with co-occurring alcohol/drug diagnoses, 1994-2002. J Subst Abuse Treat 2008; 35: $1-12$.

19 Coder B, Freyer-Adam J, Bischof G. Alcohol problem drinking among general hospital inpatients in northeastern Germany. Gen Hosp Psychiatry 2008; 30: 147-54.

20 Koskinen J, Löhönen J, Koponen H, Isohanni M, Miettunen J. Prevalence of alcohol use disorders in schizophrenia - a systematic review and meta-analysis. Acta Psychiatr Scand 2009; 120: 85-96.

21 Barry KL, Fleming MF, Greenley J, Widlak P, Kropp S, McKee D. Assessment of alcohol and other drug disorders in the seriously mentally ill. Schizophr Bull 1995; 21: 313-21.

22 Hulse GK, Saunders JB, Roydhouse RM, Stockwell TR, Basso MR. Screenin for hazardous alcohol use and dependence in psychiatric in-patients using the AUDIT questionnaire. Drug Alcohol Rev 2000; 19: 291-8.

23 McCloud A, Barnaby B, Omu N, Drummond C, Aboud A. Relationship between alcohol use disorders and suicidality in a psychiatric population. In-patient prevalence study. Br J Psychiatry 2004; 184: 439-45.

24 Kaner EF, Heather N, Brodie J, Lock CA, McAvoy BR. Patient and practitioner characteristics predict brief alcohol intervention in primary care. Br J Gen Pract 2001; 51: 822-7.

25 Aalto M, Pekuri P, Seppa K. Primary health care professionals' activity in intervening in patients' alcohol drinking during a 3-year brief intervention implementation project. Drug Alcohol Depend 2003; 69: 9-14.

26 Richmond RL, Anderson P. Research in general practice for smokers and excessive drinkers in Australia and the UK. III. Dissemination of interventions. Addiction 1994; 89: 49-62.

27 Kaner EF, Lock CA, McAvoy BR, Heather N, Gilvarry E. An RCT of three training and support strategies to encourage implementation of screening and brief alcohol intervention by general practitioners. Br J Gen Pract 1999; 49: 699-703.

28 Rydon P, Redman S, Sanson-Fisher RW, Reid AL. Detection of alcohol-related problems in general practice. J Stud Alcohol 1992; 53: 197-202.

29 Berner MM, Zeidler C, Kriston L, Mundle G, Lorenz G, Härter M. Diagnostic and treatment approaches to alcohol-related disorders. Results of a survey in general practices [in German]. Fortschr Neurol Psychiatr 2006; 74: 157-64.

30 Aalto M, Seppa K. Use of laboratory markers and the audit questionnaire by primary care physicians to detect alcohol abuse by patients. Alcohol Alcohol 2005; 40: 520-3.

31 Deitz D, Rohde F, Bertolucci D, Dufour M. Prevalence of screening for alcohol use by physicians during routine physical examinations. Alcohol Health Res World 1994; 18: 162-8.

32 Taira DA, Safran DG, Seto TB, Rogers WH, Tarlov AR. The relationship between patient income and physician discussion of health risk behaviors. JAMA 1997: 278: 1412-7.

33 Edlund MJ, Jürgen U, Wells, KB. Clinician screening and treatment of alcohol, drug, and mental problems in primary care: results from healthcare for communities. Med Care 2004; 42: 1158-66.

34 Hasin DS, Grant BF, Dufour MG, Endicott J. Alcohol problems increase while physician attention declines. 1967 to 1984. Arch Intern Med 1990; 150: $397-400$

35 Wallace $\mathrm{P}$, Cutler S, Haines A. Randomized controlled trial of general practitioner intervention in patients with excessive alcohol consumption. BMJ 1988; 297: 663-8.

36 Bertholet N, Daeppen JB, Wietlisbach V, Fleming M, Burnand B. Reduction of alcohol consumption by brief alcohol intervention in primary care: systematic review and meta-analysis. Arch Intern Med 2005; 165: 986-95. 
37 D'Onofrio G, Degutis LC. Preventive care in the emergency department: screening and brief intervention for alcohol problems in the emergency department: a systematic review. Acad Emerg Med 2002; 9: 627-38

38 Neumann $T$, Gentilello LM, Neuner B, Weiss-Gerlach $E$, Schürmann $H_{\text {, }}$ Schröder $T$, et al. Screening trauma patients with the alcohol use disorders identification test and biomarkers of alcohol use. Alcohol Clin Exp Res 2009; 33: 970-6.

39 Nielsen SD, Gluud C. Physician's information about alcohol problems at hospitalisation of alcohol misusers. Alcohol Alcohol 1992; 27: 659-65.

40 Ramsay A, Vredenburgh J, Gallagher 3rd RM. Recognition of alcoholism among patients with psychiatric problems in a family practice clinic. J Fam Pract 1983; 17: 829-32.

41 Indig D, Copeland J, Conigrave, KM, Rotenko I. Why are alcohol-related emergency department presentations under-detected? An exploratory study using nursing triage text. Drug Alcohol Rev 2008; 27: 584-90.

42 Hadida A, Kapur N, Mackway-Jones K, Guthrie E, Creed F. Comparing two different methods of identifying alcohol related problems in the emergency department: a real chance to intervene? Emerg Med J 2001; 18: 112-5.

43 Gammeter R, Nay C, Bissery A, Leutwyler J, Bonsack C, Besson J, et al. Frequency of alcohol use disorders in patients admitted in a psychiatric hospital according to admission diagnosis. Schweizer Archiv Neurol Psychiatrie 2006; 157: 290-6

44 Freimuth M. Another missed opportunity? Recognition of alcohol use problems by mental health providers. Psychotherapy 2008; 45: 405-9.

45 Vinson DC, Kruse RL, Seale JP. Simplifying alcohol assessment: two questions to identify alcohol use disorders. Alcohol Clin Exp Res 2007; 31: 1392-8.

46 Cheeta S, Drummond C, Oyefeso A, Phillips T, Deluca P, Perryman K, et al. Low identification of alcohol use disorders in general practice in England. Addiction 2008; 103: 766-73.

47 Moher D, Liberati A, Tetzlaff J, Altman DG. Preferred reporting items for systematic reviews and meta-analyses: the PRISMA statement. BMJ 2009; 339: b2535.

48 Elamin MB, Flynn DN, Bassler D, Briel M, Alonso-Coello P, Karanicolas PJ, et al. Choice of data extraction tools for systematic reviews depends on resources and review complexity. J Clin Epidemiol 2009; 62: 506-10.

49 Whiting P, Rutjes AW, Reitsma JB, Bossuyt PM, Kleijnen J. The development of QUADAS: a tool for the quality assessment of studies of diagnostic accuracy included in systematic reviews. BMC Med Res Methodol 2003; 3: 25 .

50 Reitsma JB, Glas AS, Rutjes AWS, Scholten RJPM, Bossuyt PM, Zwinderman $\mathrm{AH}$. Bivariate analysis of sensitivity and specificity produces informative summary measures in diagnostic reviews. J Clin Epidemiol 2005; 58: 982-90.

51 Higgins JPT, Thompson SG, Deeks JJ, Altman DG. Measuring inconsistency in meta-analyses. BMJ 2003; 327: 557-60.

52 Begg CB, Mazumdar M. Operating characteristics of a rank correlation test for publication bias. Biometrics 1994; 50: 1088-101.

53 Martin MJ, Heymann C, Neumann T, Schmidt L, Soost F, Mazurek B, et al. Preoperative evaluation of chronic alcoholics assessed for surgery of the upper digestive tract. Alcohol Clin Exp Res 2002; 26: 836-40.

54 Rienzi BM. Prevalence of undetected alcohol dependence in the mental health diagnostic interview. Psychol Rep 1992; 70: 913-4.

55 Gentilello LM, Villaveces A, Ries RR, Nason KS, Daranciang E, Donovan DM, et al. Detection of acute alcohol intoxication and chronic alcohol dependence by trauma center staff. J Trauma 1999; 47: 1131-5.

56 Kip MJ, Neumann T, Jugel C, Kleinwaechter R, Weiss-Gerlach E, Guill MM, et al. New strategies to detect alcohol use disorders in the preoperative assessment clinic of a German University Hospital. Anesthesiology 2008; 109: 171-9.

57 Reyna TM, Hollis HW, Hulbus RC. Alcohol-related trauma: the surgeon's responsibility. Ann Surg 1985; 201: 194-7.

58 Potvin S, Sepehry AA, Stip E. A meta-analysis of negative symptoms in dual diagnosis schizophrenia. Psychol Med 2006; 36: 431-40.

59 Potvin S, Sepehry A, Stip E. Meta-analysis of depressive symptoms in dual-diagnosis schizophrenia. Aust N Z J Psychiatry 2007; 41: 792-9.

60 Dixon L. Dual diagnosis of substance abuse in schizophrenia: prevalence and impact on outcomes. Schizophr Res 1999; 35 (suppl): 93-100.

61 Lubman DI, Hides L, Jorm AF, Morgan AJ. Health professionals' recognition of co-occurring alcohol and depressive disorders in youth: a survey of Australian general practitioners, psychiatrists, psychologists and mental health nurses using case vignettes. Aust N Z J Psychiatry 2007; 41: 830-5.

62 Weisner $\mathrm{C}$, Matzger H. Missed opportunities in addressing drinking behavior in medical and mental health services. Alcohol Clin Exp Res 2003; 27: $1132-41$.
63 National Audit Office. Reducing Alcohol Harm: Health Services in England for Alcohol Misuse. National Audit Office, 2008 (http://www.nao.org.uk/ publications/0708/reducing_alcohol_harm.aspx).

64 Booth BM, McLaughlin YS. Barriers to and need for alcohol services for women in rural populations. Alcohol Clin Exp Res 2000; 24: 1267-75.

65 Berner MM, Langlotz M, Kriston L, Härter M. Diagnostics and treatment of alcohol-related disorders: results of a representative study in psychiatric and psychotherapeutic practices [in German]. Fortschr Neurol Psychiatr 2007; 75: $18-25$.

66 Rush B, Ellis K, Crowe T, Powell L. How general practitioners view alcohol use: clearing up the confusion. Can Fam Physician 1994; 40: 1570-8.

67 Cornuz J, Ghali WA, Di Carlantonio D, Pecoud A, Paccaud F. Physicians' attitudes towards prevention: importance of intervention-specific barriers and physicians' health habits. Fam Pract 2000; 17: 535-40.

68 Wilson GB, Lock CA, Heather N, Cassidy P, Christie MM, Kaner EFS. Intervention against excessive alcohol consumption in primary health care: a survey of GPs' attitudes and practices in England 10 years on. Alcohol Alcohol 2011; 46: 570-7.

69 Aira M, Kauhanen J, Laricaara P, Rautio P. Factors influencing inquiry about patients' alcohol consumption by primary health care physicians: qualitative semi-structured interview study. Fam Pract 2003; 20: 270-5.

70 Bander KW, Goldman DS, Schwartz MA, Rabinowitz E, English JT. Survey of attitudes among three specialties in a teaching hospital toward alcoholics. J Med Educ 1987; 62: 17-24.

71 Beich A, Gannik D, Malterud K. Screening and brief intervention for excessive alcohol use: qualitative interview study of the experiences of general practitioners. BMJ 2002; 325: 1-5.

72 Thom B, Tellez C. A difficult business: detecting and managing alcohol problems in general practice. Br J Addict 1986; 81: 405-18.

73 Ferguson L, Ries R, Russo J. Barriers to identification and treatment of hazardous drinkers as assessed by urban/rural primary care doctors. J Addict Dis 2003; 22: 79-90.

74 Miller PM, Thomas SE, Mallin R. Patient attitudes towards self-report and biomarker alcohol screening by primary care physicians. Alcohol Alcohol 2006; 41: 306-10.

75 Makela P, Havio M, Seppa K. Alcohol-related discussions in health care-a population view. Addiction 2011; 106: 1239-48.

76 Rush BR, Powell LY, Crowe TG, Ellis K. Early intervention for alcohol use: family physicians' motivations and perceived barriers. CAMJ 1995; 152: 863-9.

77 Herbert C, Bass F. Early at-risk alcohol intake. Definitions and physicians' role in modifying behavior. Can Fam Phys 1997; 43: 639-44.

78 Holmqvist M, Bendtsen P, Spak F, Rommelsjö A, Geirsson M, Nilsen P. Asking patients about their drinking. A national survey among primary health care physicians and nurses in Sweden. Addicti Behav 2008; 33: 301-14.

79 National Institute on Alcohol Abuse and Alcoholism. The Physician's Guide to Helping Patients with Alcohol Problems. NIH publication 95-3769. National Institutes of Health, 1995.

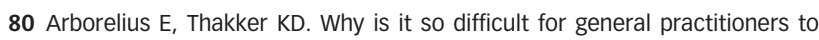
discuss alcohol with patients? Fam Pract 1995; 12: 419-22.

81 Bradley KA, Curry SJ, Koepsell TD, Larson EB. Primary and secondary prevention of alcohol problems: U.S. internist attitudes and practices. J Gen Intern Med 1995; 10: 67-72.

82 Wenrich MD, Paauw DS, Carline JD, Curtis JR, Ramsey PG. Do primary care physicians screen patients about alcohol intake using the CAGE questions? J Gen Intern Med 1995; 10: 631-4.

83 Huang M-C, Yu C-H, Chen C-T, Chen C-C, Shen WW, Chen C-H. Prevalence and identification of alcohol use disorders among severe mental illness inpatients in Taiwan. Psychiatry Clin Neurosci 2009; 63: 94-100.

84 Vinson DC, Elder NC, Werner JJ, Vorel LA, Nutting PA. Alcohol-related discussions in primary care: a report from ASPN. J Fam Pract 2000; 49: 28-33.

85 Stange KC, Zyzanski SJ, Jaen CR, Callahan EJ, Kelly RB, Gillanders WR, et al. Illuminating the 'black box'. A description of 4454 patient visits to 138 family physicians. J Fam Pract 1998; 46: 377-89.

86 Arndt S, Schultz Sk, Turvey C, Petersen A. Screening for alcoholism in the primary care setting are we talking to the right people? J Fam Pract 2002; 51: 41-6.

87 Larsson US, Saljo R, Aronsson K. Patient-doctor communication on smoking and drinking: lifestyles in medical consultations. Soc Sci Med 1987; 25: 1129-37.

88 Lawner K, Doot M, Gausas J, Doot J, See C. Implementation of CAGE alcohol screening in a primary care practice. Fam Med 1997; 29: 332-5. 
89 Bradley KA, Epler AJ, Bush KR, Sporleder JL, Dunn CW, Cochran NE, et al. Alcohol-related discussions during general medicine appointments of male VA patients who screen positive for at-risk drinking. J Gen Intern Med 2002 17: $315-26$

90 Vinson DC, Galliher JM, Reidinger C, Kappus JA. Comfortably engaging: which approach to alcohol screening should we use? Ann Fam Med 2004; 2: 398-404.

91 Reid MC, Tinetti ME, Brown CJ, Concato J. Physician awareness of alcohol use disorders among older patients. J Gen Intern Med 1998; 13: 729-34.

92 Spandorfer JM, Israel Y, Turner BJ. Primary care physicians' views on screening and management of alcohol abuse: inconsistencies with national guidelines. J Fam Pract 1999; 48: 899-902.

93 D'Amico EJ, Paddock SM, Burnam A, Kung FY. Identification of and guidance for problems drinking by general medical providers. Results from a Nationa Survey. Med Care 2005; 43: 229-36.

94 Bertakis KD, Azari R. Determinants of physician discussion regarding tobacco and alcohol abuse. J Health Commun 2007; 12: 513-25.

95 Institute of Medicine. Broadening the Base of Treatment for Alcohol Problems: Report of a Study by a Committee of the Institute of Medicine, Division of Mental Health and Behavioral Medicine. National Academy Press, 1990.

96 Council on Scientific Affairs, American Medical Association. AMA Guidelines For Physician Involvement In The Care Of Substance Abusing Patients. American Medical Association, 1979.

97 American Society of Addiction Medicine. Public Policy Statement on Screening for Addiction in Primary Care Settings. ASAM 1997.

98 Scottish Intercollegiate Guidelines Network (SIGN). The Management of Harmful Drinking and Alcohol Dependence in Primary Care. National Clinical Guidelines, 2003

99 US Preventive Services Task Force. Guide to Clinical Preventive Services (2nd edn). International Medical Publishing, 1998
100 US Preventive Services Task Force. Screening and behavioral counseling interventions in primary care to reduce alcohol misuse: recommendation statement. Ann Intern Med 2004; 140: 554-6.

101 US Dept of Health and Human Services. The Physicians' Guide to Helping Patients With Alcohol Problems. US Dept of Health and Human Services, Public Health Service, National Institutes of Health, National Institute on Alcohol Abuse and Alcoholism, 1995.

102 Beich A, Thorsen T, Rollnick S. Screening in brief intervention trials targeting excessive drinkers in general practice: systematic review and metaanalysis. BMJ 2003; 327: 536-42.

103 Phelps GL, Johnson NP. Bright light in dark places: physician recognition of alcoholism. J S C Med Assoc 1990; 86: 17-8.

104 Hoeksema $\mathrm{HL}$, De Bock GH. The value of laboratory tests for the screening and recognition of alcohol abuse in primary care patients. $J$ Fam Pract 1993; 37: 268-76.

105 Reynaud M, Schwan R, Loiseaux-Meunier M-N, Albuisson E, Deteix P. Patients admitted to emergency services for drunkenness: moderate alcohol users or harmful drinkers? Am J Psychiatry 2001; 158: 96-9.

106 Kunda S. Actual problems of clinical classification and terminology of alcoholism. Alcoholism 1996; 32: 79-93.

107 Morse RM, Flavin DK. The definition of alcoholism. JAMA 1992; 268: 1012-4.

108 Seale JP, Shellenberger S, Boltri JM, Okosun IS, Barton B. Effects of screening and brief intervention training on resident and faculty alcoho intervention behaviours: a pre- post-intervention assessment. BMC Family Pract 2005; 6: 46.

109 Anderson $\mathrm{P}$, Laurant $\mathrm{M}$, Kaner $\mathrm{E}$, Wensing M, Grol R. Engaging general practitioners in the management of hazardous and harmful alcohol consumption: results of a meta-analysis. J Stud Alcohol 2004; 65: 191-9.
Steve Peters

The psychiatrist in elite sport has an eclectic role to play. Apart from the specialist detection and treatment of mental illness, the psychiatrist can employ various psychotherapeutic techniques, within their skills, such as CBT, counselling or brief dynamic therapy. Giving athletes, and all team staff who support them, insight into the workings of the mind and application of this can significantly enhance performance in sport. Mental skills for dealing with lifestyles filled with unique stressors, and acting as a sounding board and facilitator can be invaluable to the team and individual. Being an advocate strengthens and clarifies the athlete's voice. 